Research Paper

\title{
The Epstein-Barr Virus-encoded miR-BART22 targets MAP3K5 to promote host cell proliferative and invasive abilities in nasopharyngeal carcinoma
}

\author{
Ruichao Chen ${ }^{1 *}$, Minfeng Zhang ${ }^{*}$, Qiulian Li1 ${ }^{1,5^{*}}$, Hanzhen Xiong1, Shaoyan Liu ${ }^{1}$, Weiyi Fang 3 , Qianbing \\ Zhang 3 , Zhen Liu ${ }^{1,2 \bowtie}$, Xuehu Xu ${ }^{4 \bowtie}$, Qingping Jiang ${ }^{\circledR}$ \\ 1. Department of Pathology, Third Affiliated Hospital, Guangzhou Medical University, Guangzhou, 510150, PR, China; \\ 2. Department of Pathology, Basic school, Guangzhou Medical University, Guangzhou,510000, PR China; \\ 3. Cancer Research Institute, Southern Medical University, Guangzhou, 510515, PR China; \\ 4. Gastrointestinal Department, Third Affiliated Hospital, Guangzhou Medical University, Guangzhou, 510150, PR, China; \\ 5. Department of obstetrics and gynecology, First affiliated hospital, Gannan medical university, Gannan,341000, PR, China. \\ ${ }^{*}$ These authors contributed equally to this work.
}

$\triangle$ Corresponding authors: Qingping Jiang:jiangqingping@gzhmu.edu.cn; Xuehu Xu: maxtiger@126.com; Zhen Liu:narcissus_jane@163.com.

(c) Ivyspring International Publisher. This is an open access article distributed under the terms of the Creative Commons Attribution (CC BY-NC) license (https://creativecommons.org/licenses/by-nc/4.0/). See http://ivyspring.com/terms for full terms and conditions.

Received: 2016.04.05; Accepted: 2016.10.13; Published: 2017.01.25

\begin{abstract}
miR-BART22, a new discovered Epstein-Barr virus (EBV) miRNA, is abundant in Nasopharyngeal carcinoma (NPC). It has been reported that miR-BART22 promoted the tumor development by down-modulating EBV LMP2 expression to evade the host immune response. But its cell target genes have still been obscure. We have reported an inverse correlation between the BART-22 and MAP3K5 protein expression in NPC tissues and NPC cell lines. Meanwhile, MAP3K5 protein expression level was significantly decreased in primary NPC tissues compared with nasopharyngitis when MAP3K5 mRNA expression was consistent in two group tissues. According to our data and target prediction by miRnada, we assume MAP3K5 is an important target gene of NPC. MAP3K5, also named apoptosis signal-regulating kinasel (ASK1), is an important early answer gene in P38MAPK pathway and an apoptosis-related gene. In present study, MAP3K5 was verified the target gene of miR-BART22 by luciferase assay. miRBART-22 decreased MAP3K5 protein level. Moreover, it also decreased MAP3K5 downstream gene MAP2K4 expression in P38MAPK pathway, and even their activated phosphorylation forms. Additionally, we found stable transfection of miR-BAT22 could improve tumor cells' proliferative and invasive abilities in NPC cell line 5-8F. The data highlight the role of the EBV miR-BART22 in regulating genes involving in apoptosis and some important pathways to promote cancer development. And it also raises the possibility that inhibitors of miR-BART22 can be as a therapeutic strategy for NPC and other EBV-infected tumors treatment.
\end{abstract}

Key words: Nasopharyngeal carcinoma; Epstein-Barr Virus; miRNA; MAP3K5.

\section{Introduction}

Epstein-Barr virus (EBV), a member of the gamma-herpesvirus family, is a ubiquitous human herpesvirus. It infects $>90 \%$ of the human population, usually during childhood, and persists for the whole life. Latent EBV infection is associated with several types of malignancies of epithelial and B-lymphocytic cells, including Burkitt's lymphoma (BL) [1], Hodgkin's disease [2], nasopharyngeal carcinoma (NPC) [3], and some gastric cancers [4]. NPC is one of the most frequent virus-related malignancies in humans, which occurs globally at a rate of 1 in 100,000 adults with highly elevated incidence of $20-50$ per 
100,000 in areas of southern China. This epithelial malignancy arises from the epithelium lining of the pharynx upper part behind nasal cavities. EBV DNA was identified within the most of malignant epithelial cells of undifferentiated NPC. Although EBV is not the unique etiological factor of NPC, it plays an important role in the tumor development [5]. EBV can undergo lytic replication, releasing viral progeny, or just persist latency patterns (Latency I, II, III) involving limited gene expression. EBV infection in NPC belongs to latency II [6]. It especially expresses EBNA1, LMP2, BamH1A transcripts, and partially includes LMP1. It has been profoundly validated these viral latent proteins enable to promote cell transformation, facilitate viral latency, and modulate host immunoresponse and cellular signaling (such as NF-kB, PI3K/Akt, JAK/STAT, p38/MAP, and Ras/MAPK pathways).

The EBV BARTs were first identified in NPC as multispliced transcripts [7] and then found in a wide range of EBV associated cancers [8]. It suggests that the BARTs may play an important role in NPC and other epithelial malignancies [9]. The recent discovery of BART microRNAs (miRNA) has provided new evidences for this role. MicroRNAs are single strand RNAs of short size about 22 nucleotide noncoding RNAs which are mature formation of large primary transcripts and have important regulatory function. They modulate gene expression by forming complementary duplexes with their target mRNAs, leading to translational inhibition or degradation of these mRNAs [10, 11]. MicroRNAs are involved in a broad range of biological processes contained in cancer development, such as proliferation, apoptosis, and signal transduction pathways

EBV was the first virus whose miRNAs were detected with a total of 25 premiRNAs and 44 mature miRNAs. They were divided into three clusters in the past years. One of them maps to the Bam H1 H open reading frame 1 (BHRF1) on the viral genome and is therefore called the BHRF1 cluster. The two others map to the Bam H1 A region which are derived from primary RNAs called BARTs because they are transcribed rightward from an ORF of the Bam H1 A region (Bam H1 A rightward transcripts)[12]. All data from 4 research groups showed that miRNAs from BART but no from BHRF1 cluster express in NPC, which is consistent with the Latency type II [13-16].

So far, only a limited number of EBV-miRNAs' functions and their targets have been identified in NPC. Recent discoveries suggest miR-BARTs important roles in modulating both viral and cellular gene expressions. For examples, it has been demonstrated that miR-BART1, 16, and 17 regulated the LMP1, a viral oncogene expression in NPC, by translational repression. [17]. Furthermore, miR-BART5 could down-regulate host cell genes PUMA (p53-up-regulated modulator of apoptosis) [18], which promotes NPC cell survival. miR-BART2 could down-regulate viral BALF5 mRNA by mRNA degradation on the basis of perfect complementary to the 3'UTR of this lytic gene[19, 20]. Down-modulation of LMP2A expression by miR-BART22 might permit the escape of EBV-infected NPC cells from host immune surveillance [20]. And both clusters of BART miRNAs could down-regulate Bim (Bcl-2 interacting mediator of cell death) post-transcriptionally, by part complementary to the 3'UTR [21].

These reports suggested EBV miRNAs mainly regulate viral and human genes relating to apoptosis. In NPC, the main role of EBV-encoded BART miRNAs is modulating apoptosis and host innate defence mechanisms to contribute tumorigenesis [22]. In our previous study, we found inverse correlation between miR-BART-22 and MAP3K5 protein expression in NPC tissues by immunohistochemistry [23]. In this study, we expanded the number of NPC tissues and used NPC cell lines further proved this inverse correlation by qRT-PCR and Western blot. Moreover, by bioinformatics analysis, luciferase assay, transiently transfection of EBV-miR-BART22 mimics and inhibitors, we found that MAP3K5, also named ASK1(Apoptosis signal-regulating kinase1) is one of the downstream targets of miR-BART22. MAP3K5 is not only one of important early response genes on P38MAPK and JNK pathways, but an antioncogene to promote tumor cell apoptosis in many carcinomas [24-26]. The findings in the present study highlight that miRBART22 may well have a role in NPC development through its modulation of MAP3K5 expression to inhibit tumor cell apoptosis and down-regulate MAPK pathway in NPC.

\section{Materials and Methods}

\section{Target prediction}

miRanda and Targetscan were used to predict the potential targets of EBV miRNAs. Human 3'UTR sequences were retrieved using BioMart (http://www.ensembl.org/Multi/martview) and subsequently fed into miRanda and Targetscan for prediction, with an energy threshold of $-20 \mathrm{kcal} / \mathrm{mol}$ and a cutoff score of 120 to increase the stringency. There were 13321 human genes predicted, and a part of results were listed in Table S1.

\section{Methods}

\section{Cell Lines, Xenografts, and Tumor Samples}

All cell lines were cultured in RPMI plus 10\% FBS unless otherwise specified. 293FT and 5-8F, CNE1 
and C666-1 cells were cultured in minimum essential medium plus 10\% FBS. 6 NPC and 6 nasopharyngitis(NP) fresh biopsies were obtained from Third Affiliated Hospital, Guangzhou Medical University, Guangzhou, China. Written informed consent was obtained from all of these patients to publish their case details before inclusion in the study. This research was approved by the Ethics Committee of Third Affiliated Hospital, Guangzhou Medical University, Guangzhou, China.

\section{Construction of PBABE-puro-miR-BART22 vector and retrovirus infection}

The PremiR-BART22, containing 258bp length was directly synthesized with the introduction of restriction endonuclease EcoRI/BamHI site. PremiR-BART22 was cloned into an EcoRI/BamHI -digested PBABE-puro retrovirus vector (Genechem Incorporation, Shanghai, China). The resulting retrovirus vector was transfected into 293FT cells for $84 \mathrm{hr}$ using lipofectamine 2000 (Invitrogen, Carlsbad, CA) to generate retroviral stock. An "empty" vector PBABE-puro was utilized as a negative control. After the titers were determined, retroviral particles were used to infect 5-8F cells, an NPC cell line with high metastatic potential without EBV infection. The infected cell line was named EBV-miR-BART22-5-8F and prepared for the following experiments.

\section{Plasmid Constructs}

The RNA extracted from 5-8F cells. Wild type ${ }^{\prime}$ UTR fragment of MAP3K5 were amplified by PCR from RNA, respectively. Human MAP3K5 3'-UTR DNA sequences that were predicted to interact with miR-BART22 were amplified using the following primers: (sense) 5' CCGCTCGAGCTGTTGCTCAAT CTAATCTTC $3^{\prime}$ and (antisense) 5' ATAAGAATGCG GCCGCGTTGAGAGTCTCTTTAATTTTTAG 3'. PCR products were cloned into the psi-CHECK2 vector at the same sites, and amplified, and confirmed by sequencing. The psi-CHECK2 vector was digested with restriction enzyme Xhol/NotI. These vectors were then named psi-CHECK2-MAP3K5.

\section{Luciferase Reporter Assay}

For the luciferase assay, EBV-miR-BART22-5-8F cells and $5-8 \mathrm{~F}$ cells were seeded and cultured in 24-well plates overnight and then transfected with 0.5 $\mu \mathrm{g}$ of either psi-CHECK2-MAP3K5 vector with $50 \mathrm{nM}$ of BART22-mimics or BART22-Inhibitors using siPORTTM NeoFXTM Transfection Agent (Ambion, Inc., Austin, TX, USA). Forty-eight hours after transfection, the cells were harvested and assayed with a Dual-Luciferase Reporter Assay System Kit (Promega, Madison, WI, USA). Firefly luciferase activity was then normalized to Renilla luciferase activity. The experiments were performed in triplicate and repeated twice. The data have been presented as the mean \pm standard deviation (SD).

\section{Colony formation assay}

Colony formation in soft agar EBV-miRBART22-5-8F and 5-8F were disassociated and plated at a density of 200 cells $/ 6 \mathrm{~cm}$ dish containing RPMI1640 (with 10\% inactivated fetal calf serum). On day 14 , cultured cells were stained with crystal violet and observed. The number of colonies was counted in triplicate.

\section{Boyden chamber tests}

Cell migration assays are performed using 8.0 $\mu \mathrm{m}$ pore size Transwell ${ }^{\mathrm{TM}}$ permeable supports (Corning Costar, Lowell, MA). The underside of the filters is coated with matrigel (BD bioscineces, New Jersey, America) incubated $3 \mathrm{~h}$ at $37^{\circ} \mathrm{C}$.

Trypsinized 5-8F and miR-BART22-5-8F were resuspended in serum-free medium. And then cells $(1.0 \times 104)$ were seeded in the upper chamber of inserts. After $24 \mathrm{~h}$ incubation in 5\% CO2 at $37^{\circ} \mathrm{C}$, cells remaining on the upper filter were scraped off gently using a cotton swab and the inserts were gently washed with PBS. Those cells that migrated to the lower chamber were fixed with $400 \mu \mathrm{l}$ of fixation solution (methyl alcohol: glacial acetic acid=3:1) $10 \mathrm{~min}$, stained with $400 \mu \mathrm{l}$ of hematoxylin for $20 \mathrm{~min}$. Filters are then imaged with a Zeiss LSM-510 inverted microscope (Zeiss, Germany). Five representative images (10×magnification) are randomly captured for each insert and used to manually count the number of cells. Results are presented as mean number of cells per field \pm standard deviation.

\section{Quantitative Reverse \\ Transcription-Polymerase Chain Reaction}

Real-time PCR was used to measure the expression of MAP3K5 mRNA and miR-BART22 in fresh NPC and NP tissues using SYBR Premix Ex Taq (Takara, Japan) with an Mx3000P real-time PCR system (Stratagene, La Jolla, CA, USA) and the reaction was repeated three times. The sequence for MAP3K5 sense primer was 5'-CCATCCTGGTTCCA GAACTA-3', and for antisense primer was 5'-ACATTCAGTGACCGGTGAG-3'. The sequence for miR-BART22 sense primer was $5^{\prime}$ GTGAGGCGGTTGTCACAGGT -3', and for antisense primer was 5'- AATGCGCCGCCTGTCTGCTT -3'. $\beta$-actin gene was used as an internal control.

\section{Immunohistochemistry}

Paraffin sections $(3 \mathrm{ml})$ from NPC and NP specimens were deparaffinized in $100 \%$ xylene and 
rehydrated in a descending ethanol series $(100 \%, 90 \%$, $80 \%, 70 \%$ ethanol) and water according to standard protocols. Heat-induced antigen retrieval was performed in $10 \mathrm{mMcitrate}$ buffer for $2 \mathrm{~min}$ at $100^{\circ} \mathrm{C}$. Endogenous peroxidase activity and non-specific antigen were blocked using peroxidase blocking reagent containing $3 \%$ hydrogen peroxide and serum, followed by incubation with goat anti-human MAP3K5 antibody (1:100; Abcam, Cambridge, MA, USA) overnight at $4^{\circ} \mathrm{C}$. After washing, the sections were incubated with biotinlabelled rabbit anti-goat antibody for $10 \mathrm{~min}$ at room temperature, and incubated subsequently with streptavidin-conjugated horseradish peroxidase (Maixin Inc., Fuzhou, China). The peroxidase reaction was developed using 3,3-diaminobenzidine (DAB) chromogen solution in DAB buffer substrate. Sections were then counterstained with haematoxylin, mounted in neutral gum and analysed using a bright-field microscope.

\section{Western Blot Analysis}

Western blot analysis was performed as previously described [23]. The primary antibodies used were MAP3K5 (1:2000, Abcam, Cambridge, MA, USA ), MAP2K4 (1:2000, Abcam, Cambridge, MA, USA), phospho-MAP3K5 (ser473; 1:1000; Abcam, Cambridge, MA, USA ), phospho-MAP2K4(1:2000, Abcam, Cambridge, MA, USA), EGFP (1:20,000 dilution; Clontech Inc, Mountain View, USA) and $\beta$-actin (1:30,000; Sigma, New York, USA). All horseradish peroxidase-conjugated secondary antibodies used were purchased from DAKO $(1: 20,000)$. The density of Western blot signals was measured by Image J software.

\section{Statistical analysis}

The data were expressed as the mean \pm SD of at least three separate experiments. Statistical significance was determined using Student's t-test (two-tailed) or analysis of variance (ANOVA) for functional analyses. All data were expressed as the mean \pm standard deviation (SD), and all data are represented as the average of at least three experiments, with each experiment performed in triplicate. In bar graphs, * and ** indicate $P<0.05$ and $P<0.01$, respectively. A $P$ value $<0.05$ was considered to indicate statistical significance.

\section{Results}

\section{EBV miR-BART22 inhibits MAP3K5 translation in NPC tissues}

6 NPC and 6 NP tissues were extracted RNA and protein respectively. EBV miR-BART22 and MAP3K5 mRNA were detected by qRT-PCR, and MAP3K5 protein by western blot. The results show expression of miR-BART22 in 6 NPC tissues was much higher than that in $6 \mathrm{NP}$ tissues (Fig. 1A), and MAP3K5 mRNA expression was consistent in NPC and NP tissues (Fig. 1B). In the same time, the expression of MAP3K5 protein in $6 \mathrm{NP}$ tissues was significantly higher than that in 6 NPC tissues (Fig. 1C). By immunohistochemistry, we also found MAP3K5 strongly stained in $6 \mathrm{NP}$ tissues and faint positive or negative in 6 NPCs (Fig. 1-D). The expression of miR-BART22 and MAP3K5 protein level has statistically difference in NPC tissues when there was no significant difference between miR-BART22 and MAP3K5 mRNA expression level. Then we detected expression of miR-BART22 and MAP3K5 in NPC cell lines, and found EBV-miR-BART22 was higher in the EBV infected cell line C666-1 than that in 5-8F and CNE1(P<0.01). MAP3K5 mRNA level was similar in three lines when Protein level was lower in C666-1 than in the other two cell lines(Fig. 1E-F). The results suggested EBV miR-BART22 inhibits MAP3K5 translation in NPC tissues and cell lines.

\section{MAP3K5 is one of target gene of EBV-miR-BAR22}

To identify MAP3K5 is one of target gene of EBV-miR-BAR22, we performed luciferase assay using MAP3K5-3'UTR reporter plasmids with miR-BART22 mimics and inhibitors. Results showed that compared with EBV-miR-BART22-5-8F, the cell lines added to BART22 mimics decreased luciferase activity, when those added to BART22 inhibitors increased luciferase activity (Fig. 2A). Similarly, luciferase activity of cell line $5-8 \mathrm{~F}$ without EBV-miR-BART22 was higher than that in 5-8F added with miR-BART22 mimics and lower than that added with miR-BART22 inhibitors (Fig. 2B).

To further examine the relationship between EBV-miR-BART22 and MAP3K5, 5-8F cells were transiently transfected with EBV-miR-BART22 mimics, and we then observed MAP3K5 protein level was dropped when mRNA level was not changed compared to the control group $(\mathrm{P}<0.01)$ (Fig. 2C). Conversely, when C666-1 transfected with EBV-miR-BART22 inhibitor, MAPK5 protein expression increased $((\mathrm{P}<0.01)$ (Fig. 2D).

\section{Modulation of MAP3K5 and MAP2K4 expression by miR-BART22.}

MAP3K5 its downstream gene on MAPK pathway MAP2K4, and their phosphoralation levels, called P-MAP3K5 and P-MAP2K4 were detected by western blot in 5-8F-BAR22 and wild 5-8F cell lines. It was found that the protein expression of these genes were lower in 5-8F-BART22 than in 5-8F. Moreover, 
MAP2K4 and P-MAP2K4 levels were even lower than expression level fo MAP3K5 and P-MAP3K5 (Fig. 3).

\section{EBV miR-BART22 promotes proliferation and invasive ability of cancer cells.}

A significant difference was found in colony formation efficiency between two cell lines
miR-BART22-5-8F and 5-8F. The CFE of miR-BART22-5-8F was higher than that of 5-8F (Fig. $4 \mathrm{~A})$. Boyden chamber tests show invasive ability of miR-BART22-5-8F was stronger than 5-8F (Fig. 4B).
A

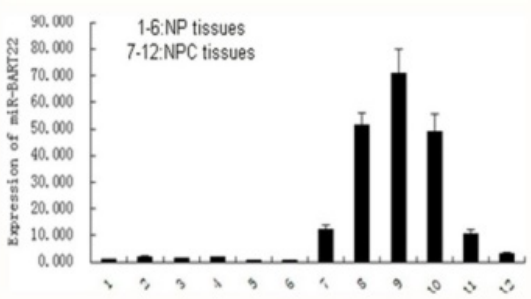

C
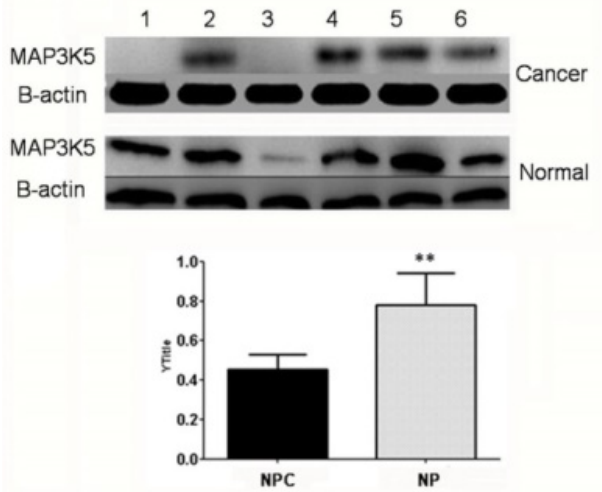

E

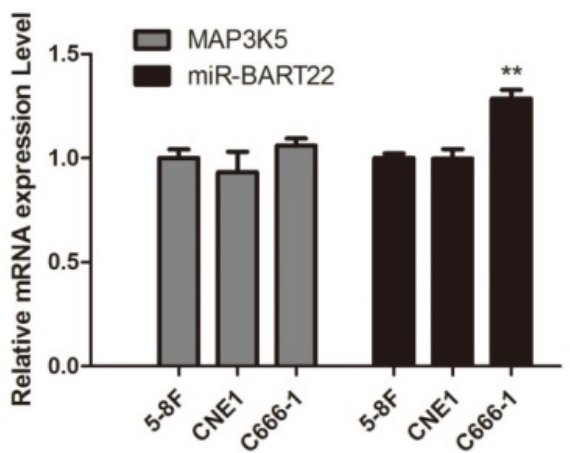

B

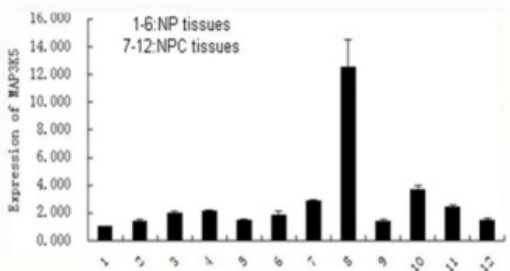

D

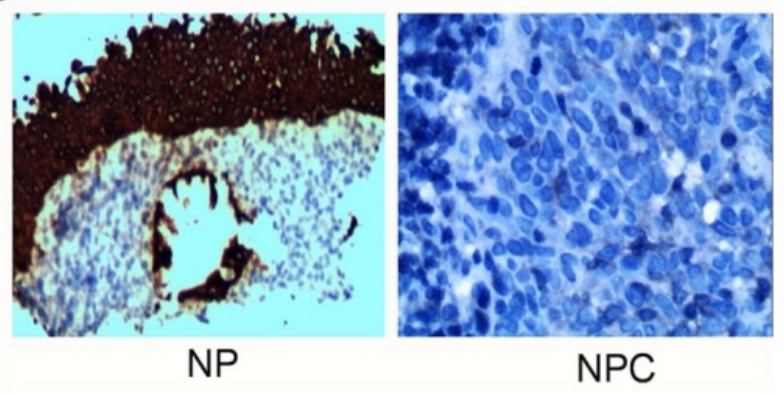

NPC

Figure 1. EBV miR-BART22 inhibits MAP3K5 translation in NPC tissues. A.miR-BART22 expression in 6 NPC tissues was much higher than that in 6 NP tissues. B. MAP3K5 mRNA expression was consistent in NPC and NP tissues. (In A,B 1-6 lanes: NP tissues. 7-12 Lanes: NPC tissues.) C. The level of MAP3K5 protein in 6 NP tissues was significantly higher than that in 6 NPC tissues. D. MAP3K 5 strongly stained in 6 NP tissues and faint positive or negative in 6 NPCs by immunohistochemistry(ISH $\times 400)$. E. The expression of MAP3K5 mRNA and EBV-miR-BART22 in NPC cell lines 5-8F, CNE1 and C666-1. F. MAP3K5 protein expression in NPC cell lines 5-8F, CNE1 and C666-1 (**P<0.001). 
A

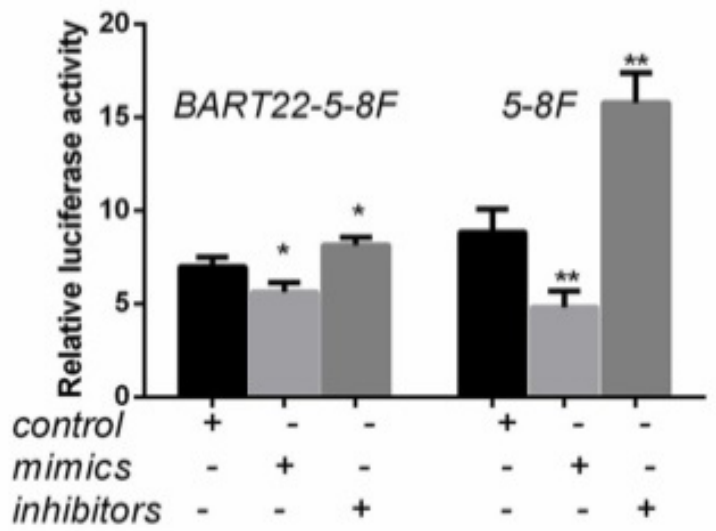

C

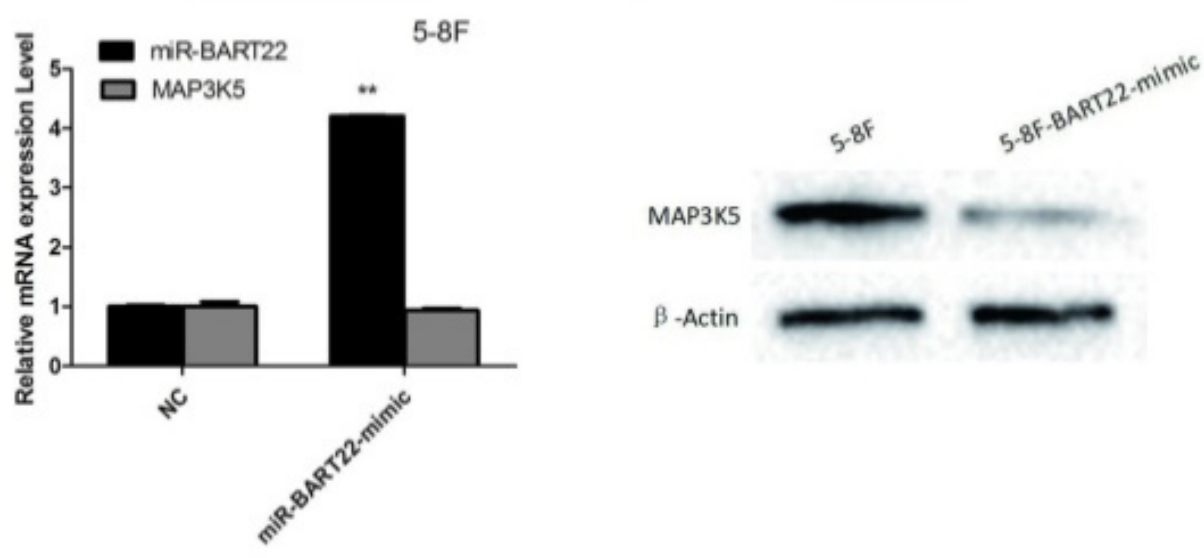

D

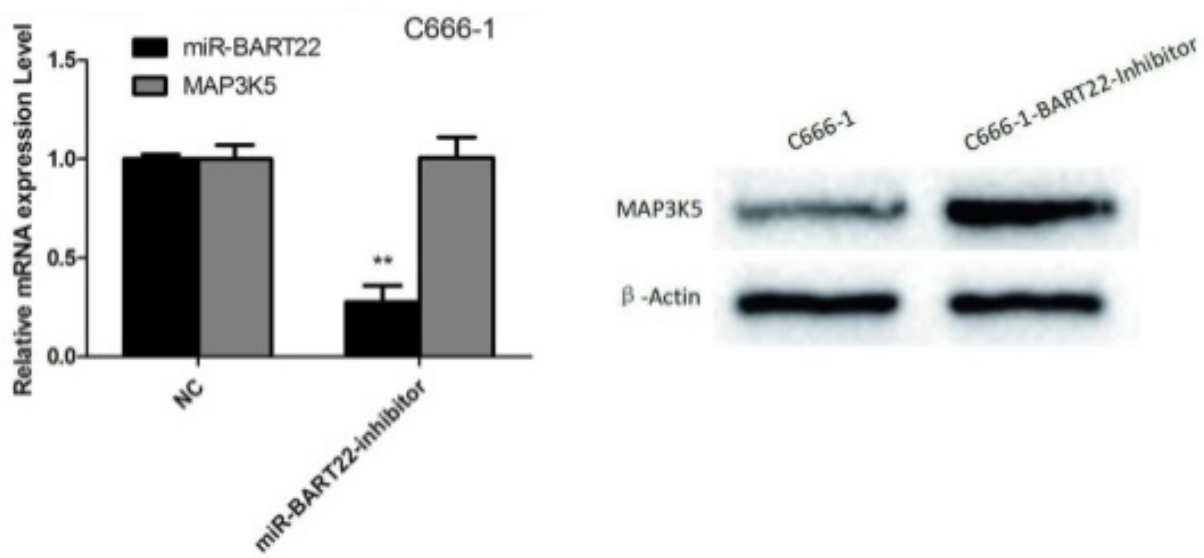

Figure 2. Luciferase analysis suggested MAP3K5 is a target gene of miR-BART22. A. Luciferase analysis of the interaction between miR-BART22 and its target sequences in the 3'-UTR of MAP3K5 mRNA in EBV-miR-BART22-5-8F, EBV-miR-BART22-5-8F added with miR-BAR22-mimics and that added with miR-BART22-inhibitors. B. Luciferase analysis in 5-8F, 5-8F added with miR-BAR22-mimics and that added with miR-BART22-inhibitors. The Renilla luciferase activity is expressed as relative luminescence units (RLU) normalized with a firefly luciferase construct. Values are shown as means \pm standard deviation. C. EBV-miR-BART22 mimics transiently transfected into 5-8F, MAP3K5 mRNA and protein was detected. D. EBV-miR-BART22 inhibitor transiently transfected into C666-1, the level of MAP3K5 mRNA and protein was detected.

\section{Discussion}

In this study, we showed that EBV miR-BART22 targets the 3' UTR of MAP3K5 gene and modulate MAP3K5 expression on posttranscriptional level. MAP3K5(ASK1) is a MAP Kinase Kinase kinase (MAP3K) and extensively expressed in tissues [29]. It can be activated by all kinds of stress stimulation, such as reactive oxygen species (ROS), TNF-a and endotoxin. It was the early answer gene in p38MAPK and JNK pathways. It was the accumulation point of cell proliferation, invasion, differentiation, senescence, and apoptosis provoked by extracellular signal. Moreover, it is an indispensable gene of 
apoptosis, and can influence cell survival, differentiation and autoimmune response [30]. According to the researches of enteritis and intestinal carcinoma, the tumor formation abilities of mice with knockout MAP3K5 were higher than those control mice [31]. In skin cancer, MAP3K5 could promote apoptosis as tumor suppressor gene [32].

In NPC, EBV latent infection resulted in the activation of STAT3 and NFkappaB signal cascades and induced the suppression of p38MAPK activities [33]. However, so far, the mechanism is not clear how EBV modulated theses pathways.

Through analysis by miRanda and Targetscan, we found MAP3K5 is one of the possible target genes of EBV-miR-BART22. EBV-miR-BART22 was consistently expressed in primary NPC tissues and not in nasopharyngitis. In line with our findings, Lung et al and Zhu et al have reported the miR-BART22 expression in NPC cell lines and primary tissues $[13,20]$. MiR-BART22 was found to be highly expressed in almost all NPC biopsies. An inverse correlation between the BART-22 and MAP3K5 protein expression were observed, when MAP3K5 mRNA expression was not significantly changed between NPC tissues and nasopharyngitis. And in NPC cell lines, we also found MAP3K5 protein expression was lower in C666-1 than that in 5-8F and CNE1 when mRNA expression was similar.

By luciferase assay using MAP3K5-3'UTR reporter plasmids with miR-BART22 mimics and inhibitors, the present study ensured miR-BART22 regulated MAP3K5 on posttranscriptional level. MiR-BART22 not only inhibited MAP3K5 but MAP2K4 (downstream gene in p38MAPK pathway) and their phosphorylated forms when their expression was compared between 5-8F NPC cell line and miR-BART22-5-8F. Furtherly, when we transiently transfected EBV-miR-BART22-mimics and inhibitor into 5-8F and C666-1 respectively, it showed MAP3K5 protein expression changed in conversely direction.

Additionally, stable transfection of EBV-miR-BAT22 could improve tumor abilities of proliferation and invasion. These functions may be partly carried out by regulating MAP3K5. In concordance with previous reports, EBV-miRNAs can target genes mediated apoptosis such as BIM, PUMA, MAP3K5 in the progression of EBV-infected tumors. The data also raise the possibility that inhibitors of
miR-BARTs can be as a therapeutic strategy for NPC and other EBV-infected tumors treatment.

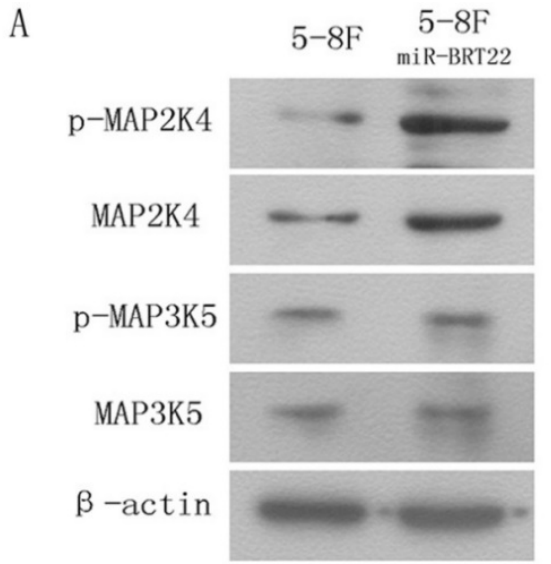

B
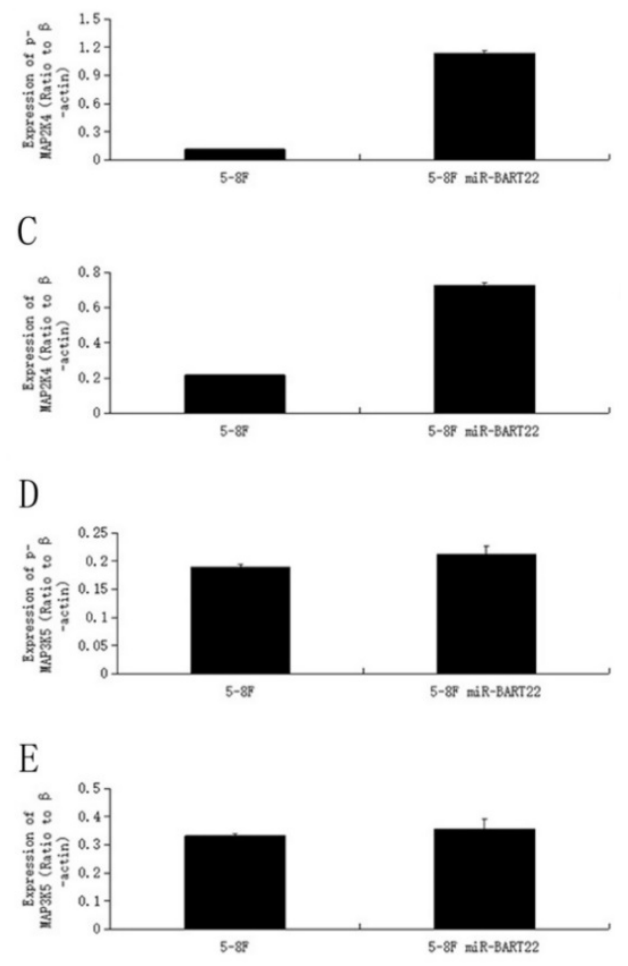

Figure 3. Western blot analysis indicated that the expression level of MAP3K5 and MAP2K4 protein and their phosphoralation forms is higher in 5-8F than that in miR-BART22-5-8F. A. Western blot analysis of four kinds of protein in miR-BART22-5-8F versus 5-8F. B-C. column diagram of MAP3K5 and P-MAP3K5 protein expression in miR-BART22-5-8F versus $5-8 \mathrm{~F}$. D-E. Column diagram of MAP2K 4 and P-MAP2K4 protein expression in miR-BART22-5-8F versus $5-8 \mathrm{~F}$. 

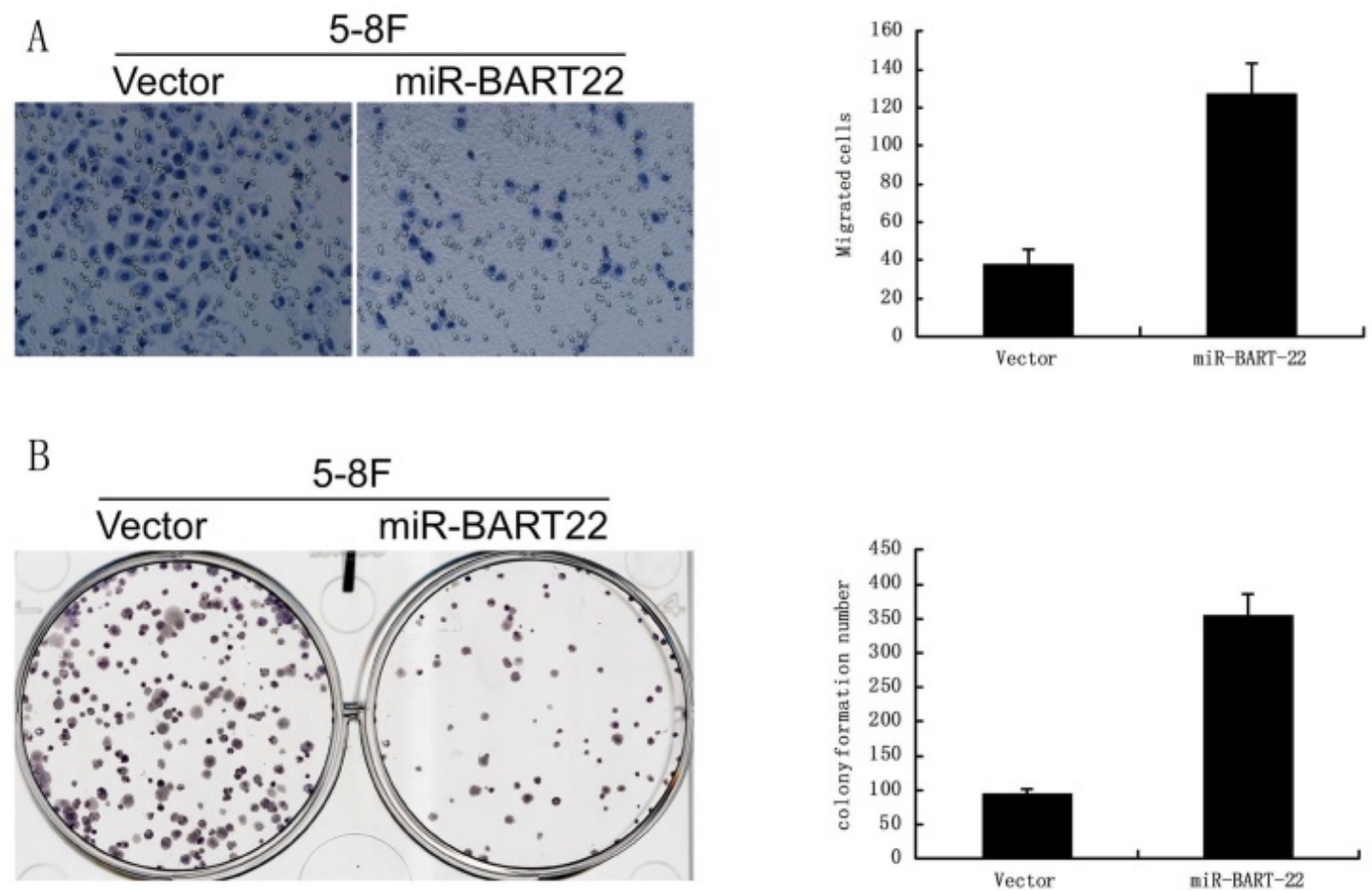

Figure 4. EBV miR-BART22 promotes proliferation and invasive ability of cancer cells. A. Colony formation efficiency was higher in the cell lines miR-BART22-5-8F than that in 5-8F. B. Boyden chamber tests show invasive ability of miR-BART22-5-8F was stronger than 5-8F.

\section{Supplementary Material}

Table S1. http://www.jcancer.org/v08p0305s1.xls

\section{Abbreviations}

NPC, nasopharyngeal carcinoma; EBV, Epstein-Barr Virus; ASK1, apoptosis signal-regulating kinase1; ISH: in situ hybridization.

\section{Acknowledgments}

This study was supported by National Nature Science Fund of China (No. 81102061,30971438,), Guangdong Province Breeding Project Plan (No. LYM11102), Guangdong Province Education Foundation (No.2014KTSCX102, No.2014KTSCX107), The Fund of Guangdong Science and Technology department (No.2014A020212342).

\section{Competing Interests}

The authors have declared that no competing interest exists.

\section{References}

1. Epstein MA, Achong BG, Barr YM. VIRUS PARTICLES IN CULTURED LYMPHOBLASTS FROM BURKITT'S LYMPHOMA. Lancet. 1964; 1(7335):702-703.

2. Weiss LM, Strickler JG, Warnke RA, Purtilo DT, Sklar J. Epstein-Barr viral DNA in tissues of Hodgkin's disease. Am J Pathol. 1987; 129(1):86-91.

3. Desgranges C, Wolf H, De-The G, Shanmugaratnam K, Cammoun N, Ellouz R, Klein G, Lennert K, Munoz N, Zur Hausen H. Nasopharyngeal carcinoma. X. Presence of epstein-barr genomes in separated epithelial cells of tumours in patients from Singapore, Tunisia and Kenya. Int J Cancer. 1975; 16(1):7-15.
4. Shibata D, Weiss LM. Epstein-Barr virus-associated gastric adenocarcinoma. Am J Pathol. 1992; 140(4):769-774.

5. Raab-Traub N, Flynn K, Pearson G, Huang A, Levine P, Lanier A, Pagano J. The differentiated form of nasopharyngeal carcinoma contains Epstein-Barr virus DNA. Int J Cancer. 1987; 39(1):25-29.

6. Delecluse HJ, Feederle R, O'Sullivan B, Taniere P. Epstein Barr virus-associated tumours: an update for the attention of the working pathologist. J Clin Pathol. 2007; 60(12):1358-1364.

7. Young LS, Rickinson AB. Epstein-Barr virus: 40 years on. Nat Rev Cancer. 2004; $4(10): 757-768$.

8. Harn HJ, Chang JY, Wang MW, Ho LI, Lee HS, Chiang JH, Lee WH. Epstein-Barr virus-associated gastric adenocarcinoma in Taiwan. Hum Pathol. 1995; 26(3):267-271.

9. Karran L, Gao Y, Smith PR, Griffin BE. Expression of a family of complementary-strand transcripts in Epstein-Barr virus-infected cells. Proc Natl Acad Sci U S A. 1992; 89(17):8058-8062

10. Bartel DP. MicroRNAs: genomics, biogenesis, mechanism, and function. Cell. 2004; 116(2):281-297.

11. Cullen BR. Viruses and microRNAs. Nat Genet.2006; 38 Suppl:S25-30.

12. Edwards RH, Marquitz AR, Raab-Traub N. Epstein-Barr virus BART microRNAs are produced from a large intron prior to splicing. J Virol. 2008; 82(18):9094-9106.

13. Zhu JY, Pfuhl T, Motsch N, Barth S, Nicholls J, Grasser F, Meister G. Identification of novel Epstein-Barr virus microRNA genes from nasopharyngeal carcinomas. J Virol. 2009; 83(7):3333-3341.

14. Chen SJ, Chen GH, Chen YH, Liu CY, Chang KP, Chang YS, Chen HC. Characterization of Epstein-Barr virus miRNAome in nasopharyngeal carcinoma by deep sequencing. PLoS One. 2010; 5(9).

15. Cosmopoulos K, Pegtel M, Hawkins J, Moffett H, Novina C, Middeldorp J, Thorley-Lawson DA. Comprehensive profiling of Epstein-Barr virus microRNAs in nasopharyngeal carcinoma. J Virol. 2009; 83(5):2357-2367.

16. Wong AM, Kong KL, Tsang JW, Kwong DL, Guan XY. Profiling of Epstein-Barr virus-encoded microRNAs in nasopharyngeal carcinoma reveals potential biomarkers and oncomirs. Cancer. 2012; 118(3):698-710.

17. Lo AK, To KF, Lo KW, Lung RW, Hui JW, Liao G, Hayward SD. Modulation of LMP1 protein expression by EBV-encoded microRNAs. Proc Natl Acad Sci U S A. 2007; 104(41):16164-16169.

18. Choy EY, Siu KL, Kok KH, Lung RW, Tsang CM, To KF, Kwong DL, Tsao SW, Jin DY. An Epstein-Barr virus-encoded microRNA targets PUMA to promote host cell survival. J Exp Med. 2008; 205(11):2551-2560.

19. Barth S, Pfuhl T, Mamiani A, Ehses C, Roemer K, Kremmer E, Jaker C, Hock J, Meister G, Grasser FA. Epstein-Barr virus-encoded microRNA miR-BART2 down-regulates the viral DNA polymerase BALF5. Nucleic Acids Res. 2008; 36(2):666-675.

20. Lung RW, Tong JH, Sung YM, Leung PS, Ng DC, Chau SL, Chan AW, Ng EK, Lo KW, To KF. Modulation of LMP2A expression by a newly identified 
Epstein-Barr virus-encoded microRNA miR-BART22. Neoplasia. 2009; 11(11):1174-1184.

21. Marquitz AR, Mathur A, Nam CS, Raab-Traub N. The Epstein-Barr Virus BART microRNAs target the pro-apoptotic protein Bim. Virology. 2011; 412(2):392-400.

22. Lo AK, Dawson CW, Jin DY, Lo KW. The pathological roles of BART miRNAs in nasopharyngeal carcinoma. J Pathol. 2012; 227(4):392-403.

23. Jiang QP, Liu SY, He XF, Peng J, Xiong HZ, Xiong ZT, Yang YX. Relationship between MAP3K5 and Epstein-Barr virus-encoded miR-BART22 expression in nasopharyngeal carcinoma. Nan Fang Yi Ke Da Xue Xue Bao. 2011; 31(7):1146-1149.

24. Chibon F, Mariani O, Derre J, Mairal A, Coindre JM, Guillou L, Sastre X, Pedeutour F, Aurias A. ASK1 (MAP3K5) as a potential therapeutic target in malignant fibrous histiocytomas with 12q14-q15 and $6 \mathrm{q} 23$ amplifications. Genes Chromosomes Cancer. 2004; 40(1):32-37.

25. Prickett TD, Zerlanko B, Gartner JJ, Parker SC, Dutton-Regester K, Lin JC, Teer JK, Wei X, Jiang J, Chen G et al. Somatic Mutations in MAP3K5 Attenuate Its Proapoptotic Function in Melanoma through Increased Binding to Thioredoxin. J Invest Dermatol. 2014; 134(2):452-60.

26. Pressinotti NC, Klocker H, Schafer G, Luu VD, Ruschhaupt M, Kuner R, Steiner E, Poustka A, Bartsch G, Sultmann H. Differential expression of apoptotic genes PDIA3 and MAP3K5 distinguishes between low- and high-risk prostate cancer. Mol Cancer. 2009; 8:130.

27. John B, Enright AJ, Aravin A, Tuschl T, Sander C, Marks DS. Human MicroRNA targets. PLoS Biol. 2004; 2(11):e363.

28. Rehmsmeier M, Steffen P, Hochsmann M, Giegerich R. Fast and effective prediction of microRNA/target duplexes. RNA. 2004; 10(10):1507-1517.

29. Tobiume K, Matsuzawa A, Takahashi T, Nishitoh H, Morita K, Takeda K, Minowa O, Miyazono K, Noda T, Ichijo H. ASK1 is required for sustained activations of JNK/p38 MAP kinases and apoptosis. EMBO Rep. 2001; 2(3):222-228.

30. Ichijo H, Nishida E, Irie K, ten Dijke P, Saitoh M, Moriguchi T, Takagi M, Matsumoto K, Miyazono K, Gotoh Y. Induction of apoptosis by ASK1, a mammalian MAPKKK that activates SAPK/JNK and p38 signaling pathways. Science. 1997; 275(5296):90-94.

31. Hayakawa Y, Hirata Y, Nakagawa H, Sakamoto K, Hikiba Y, Otsuka M, Ijichi $\mathrm{H}$, Ikenoue $\mathrm{T}$, Tateishi $\mathrm{K}$, Akanuma $\mathrm{M}$ et al. Apoptosis signal-regulating kinase 1 regulates colitis and colitis-associated tumorigenesis by the innate immune responses. Gastroenterology. 2010; 138(3):1055-1067 e1051-1054.

32. Iriyama T, Takeda K, Nakamura H, Morimoto Y, Kuroiwa T, Mizukami J, Umeda T, Noguchi T, Naguro I, Nishitoh $\mathrm{H}$ et al. ASK1 and ASK2 differentially regulate the counteracting roles of apoptosis and inflammation in tumorigenesis. EMBO J. 2009; 28(7):843-853.

33. Lo AK, Lo KW, Tsao SW, Wong HL, Hui JW, To KF, Hayward DS, Chui YL, Lau YL, Takada $\mathrm{K}$ et al. Epstein-Barr virus infection alters cellular signal cascades in human nasopharyngeal epithelial cells. Neoplasia. 2006; 8(3):173-180. 